\title{
青藏高原唐古拉山地区降雪中 $\delta^{18} \mathrm{O}$ 特征 及其与水汽来源的关系
}

\author{
姚售株 丁良福 蒲建辰 上田丰* 大姻指夫* 刘景寿 杨志红 \\ (中国科学院兰州冰川冻土研究所,兰州 73000 ; *日本名古虽大学水睡研究所)
}

关勧词 $\delta^{\mathrm{H} O} \mathrm{O} 、$ 水汽来源

本文以 1989 年中日青藏高原冰川考察研究期间所得到的资料为基础, 讨论该地区降雪中 同位素 ( $\left.\delta^{\mathrm{lio}} \mathrm{O}\right)$ 的特征及其与水汽来源的关系.

\section{一、采样与分析}

采样方法为定点不同时间采样法. 主要目的是了解 $\delta^{18} \mathrm{O}$ 随时间变化的特征. 采样点是 在唐古拉山口附近的冬克玛底谷地 (冬克玛底冰川下游). 采样的具体步㧱是事先将一木板或 塑料槽放在平地, 每次采样前的程序是准备 $100 \mathrm{ml}$ 和 $200 \mathrm{ml}$ 塑料水样瓶, 记下降雪的不同起 论时间, 在降雪间歇时将木板上或塑料槽上的雪采集装人 $200 \mathrm{ml}$ 水样瓶，待融化后再装人 100 $\mathrm{ml}$ 水样瓶. 因为在雪样采集点安装有自动气象记录仪(记录时间间隔为 $10 \mathrm{~min}$ ), 随时间变化 的各气象要素都可通过气象记录求得. 分析 ${ }^{18} \mathrm{O}$ 所需要的样品从野外远回后, 放人低温室冻 结保存,在分析前数天取出融化,以备分析.

样品的分析是用 Mat-251 质谱仪, 其精度为 $0.025 / 1000$ 。

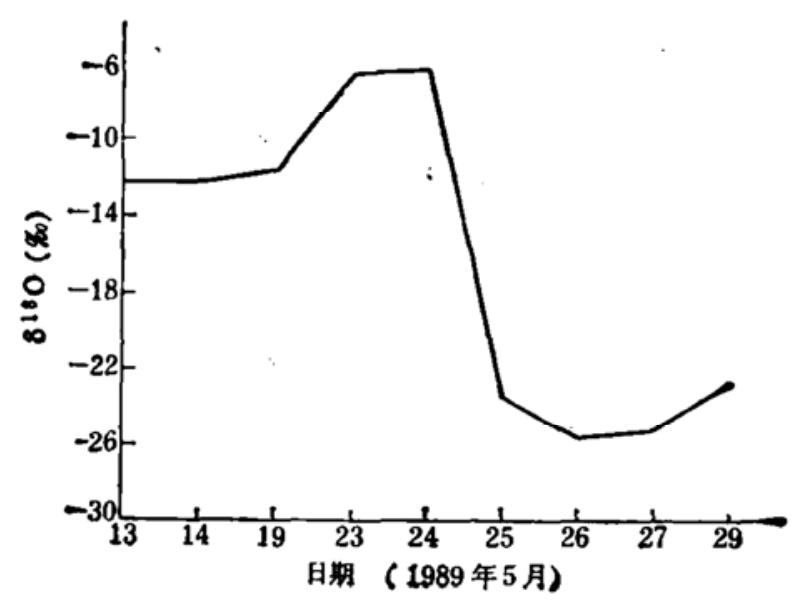

图 11989 年 5 月唐古拉山降鲁中 $\sigma^{110}$ (司同位索值)的变化

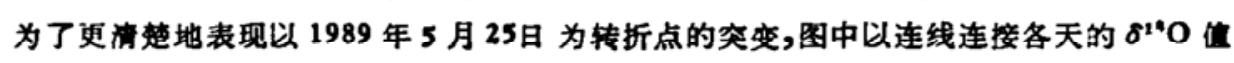

本文 1990 年 8 月 20 日收到. 


\section{二、研 究 结 果}

$\delta^{18} \mathrm{O}$ 随时间变化的分析结果表明，不同时段降雪中的 $\delta^{18} \mathrm{O}$ 值差异很大. 样品采集 始于 1989 年 5 月 13 日,止于 1989 年 6 月 11 日. 这期间的降雪是由好几次天气过程造成的. 从 分析结果看, 各次天气过程降雪中的 $\delta^{18} \mathrm{O}$ 都有一定的差异, 但最为明显的是以 1989 年 5 月 25 日为转折点的 $\delta^{18} \mathrm{O}$ 的突变. 为了便于比较和更醒目地表示以 5 月 25 日为转折点的 $\delta^{18} \mathrm{O}$ 变化, 根据作者在本研究区获得的温度下降 $1{ }^{\circ} \mathrm{C}, \delta^{18} \mathrm{O}$ 减少 $0.5 \%$ (1989 年 4 月 25 日以前)和 温度降低 $1^{\circ} \mathrm{C}, \delta^{19} \mathrm{O}$ 减少 $2 \%$ (1989 年 4 月 25 日以后)的关系, 我们把各次降雪中的 $\delta^{18} \mathrm{O}$ 值都 换算到相应于该地区地面温度为 $0^{\circ} \mathrm{C}$ 时的 $\delta^{18} \mathrm{O}$ 值, 并绘成图 1. 从图 1 可以看出, 25 日以前, 降雪中相应于地面温度 $0^{\circ} \mathrm{C}$ 时的 $\delta^{18} \mathrm{O}$ 比较富集,达 $-10.30 \%$ 。但 25 日以后, $\delta^{18} \mathrm{O}$ 突然减小, 低至 $-24.5 \%$ 。

\section{三、讨 论}

$\delta^{18} \mathrm{O}$ 变化最主要的影响因子是温度. 在某一固定地点, 温度对 $\delta^{18} \mathrm{O}$ 的影响是通过三个方 面来实现的. 第一, 汽团类型; 第二, 降水(降雪)时的温度; 第三, 水汽源地的温度. 研究同一 天气过程所产生的降水时, 以上三方面的第三方面可以忽略不计(因这方面的影响比起其它两 方面的影响是十分微小的). 第一、第二两方面总体来说对 $\delta^{19} \mathrm{O}$ 有同等重要的作用. 降水(雪) 时的气温 (更精确地讲是水汽凝结温度) 直接控制水汽中 $\delta^{18} \mathrm{O}$ 的分馏过程, 而汽团的类型则直

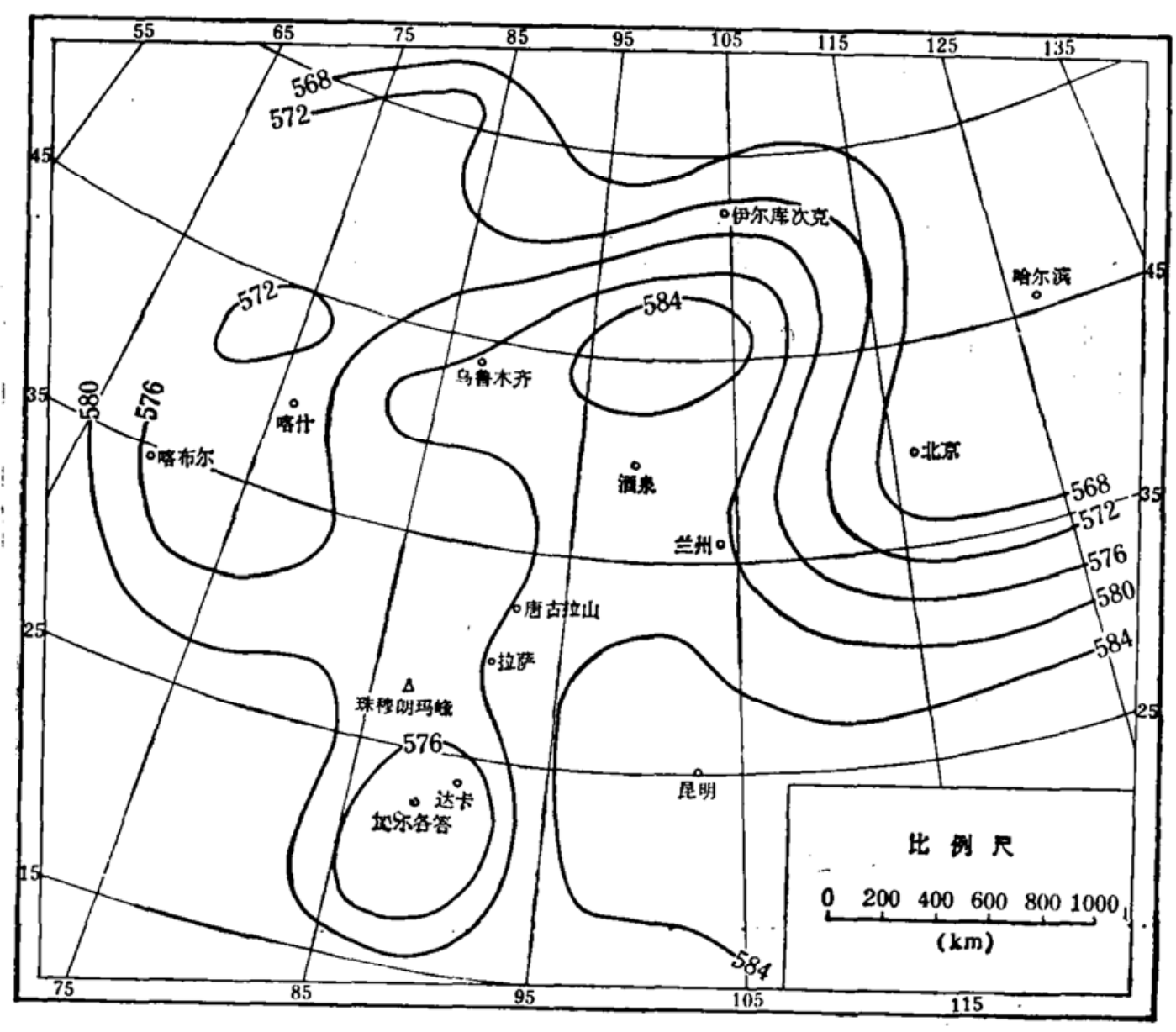

图 21989 年 5 月 24 日青葴高原及其附近地区天气形势 (08 时) 
表 1 青藏高原唐古拉山 1989 年 5 月降雪中 $\delta^{\prime \prime} O$ 变化

\begin{tabular}{|c|c|c|c|c|c|c|}
\hline 日 & 时.分 & 渴度(จ) & $\delta^{12} \mathrm{O}(\%)$ & 到 $0 \underset{(\% \circ)}{\mathrm{C} \text { 的 } \delta^{12} \mathrm{O}}$ & 平均 & 备注 \\
\hline $\begin{array}{l}13 \\
13\end{array}$ & $\begin{array}{c}\text { 15-16 时 } \\
\text { 日平均 }\end{array}$ & $\begin{array}{r}0.70 \\
-4.60\end{array}$ & $\begin{array}{l}-12.91 \\
-11.20\end{array}$ & $\begin{array}{r}-13.32 \\
-8.49\end{array}$ & -12.06 & \\
\hline $\begin{array}{l}14 \\
14 \\
14\end{array}$ & $\begin{array}{c}3-4 \text { 时 } \\
\text { 展 } \\
10-10.30\end{array}$ & $\begin{array}{l}-6.10 \\
-5.30 \\
-5.80\end{array}$ & $\begin{array}{l}-16.14 \\
-18.94 \\
-11.2\end{array}$ & $\begin{array}{r}-12.84 \\
-15.81 \\
-7.78\end{array}$ & -12.14 & \\
\hline 19 & 3 时 & -8.20 & -16.64 & -11.60 & -11.6 & \\
\hline $\begin{array}{l}23 \\
23 \\
23\end{array}$ & $\begin{array}{c}5-6 \text { 时 } \\
5-5.30 \\
11-11.15\end{array}$ & $\begin{array}{l}0.55 \\
0.50 \\
1.40\end{array}$ & $\begin{array}{l}-6.91 \\
-4.3 \\
-6.73\end{array}$ & $\begin{array}{l}-7.24 \\
-4.60 \\
-7.56\end{array}$ & -6.47 & \\
\hline $\begin{array}{l}24 \\
24 \\
24\end{array}$ & $\begin{array}{c}7.30-8.20 \\
9.15-9.45 \\
9-9.15 \\
\end{array}$ & $\begin{array}{r}-0.20 \\
0.30 \\
0.40\end{array}$ & $\begin{array}{l}-5.15 \\
-7.15 \\
-6.28\end{array}$ & $\begin{array}{l}-5.03 \\
-7.33 \\
-6.52\end{array}$ & -6.29 & \\
\hline $\begin{array}{l}25 \\
25\end{array}$ & $\begin{array}{r}19.10-19.45 \\
21.40-22.29 \\
\end{array}$ & $\begin{array}{l}4.40 \\
0.80 \\
\end{array}$ & $\begin{array}{l}-15.78 \\
-21.07 \\
\end{array}$ & $\begin{array}{l}-23.98 \\
-23.30\end{array}$ & -23.64 & \\
\hline $\begin{array}{l}26 \\
26 \\
26\end{array}$ & $\begin{array}{c}3-4 \\
15.40-15.45 \\
\text { 日平均 }\end{array}$ & $\begin{array}{l}0.35 \\
1.70 \\
0.40\end{array}$ & $\begin{array}{l}-22.58 \\
-22.09 \\
-27.64\end{array}$ & $\begin{array}{l}-23.28 \\
-25.49 \\
-28.44\end{array}$ & -25.74 & \\
\hline $\begin{array}{l}27 \\
27 \\
27\end{array}$ & $\begin{array}{c}2 \text { 时 } \\
2-3 \text { 时 } \\
\text { 晚 }\end{array}$ & $\begin{array}{l}-1.50 \\
-1.50 \\
-1.90\end{array}$ & $\begin{array}{l}-26.01 \\
-27.83 \\
-31.90\end{array}$ & $\begin{array}{l}-23.01 \\
-24.83 \\
-28.1\end{array}$ & -25.31 & \\
\hline 29 & 11 时 & 1.80 & -26.26 & -22.66 & -22.66 & \\
\hline
\end{tabular}

表 25 月 13 日至 25 日唐古拉观浰点及邻近气象站温度、气压日平均值变化

\begin{tabular}{|c|c|c|c|c|c|}
\hline \multirow{2}{*}{ 日 } & \multirow{2}{*}{ 沦沦河温度 $\left.{ }^{\circ} \boldsymbol{C}\right)$} & \multicolumn{2}{|c|}{ 沘沦 河 } & \multicolumn{2}{|c|}{ 五 道 梁 } \\
\hline & & 温度( ${ }^{(0)}$ ) & そ医 $\left(\mathrm{mhPa}_{2}\right)$ & 㬈度 & 臣 $(\mathrm{mhPa})$ \\
\hline 3.13 & -4.5 & -3.1 & 5856 & -2.9 & 5796 \\
\hline 3.14 & -5.8 & -4.5 & 5830 & -6.3 & 5776 \\
\hline 5.15 & -8.4 & -6.9 & 5864 & -7.9 & 5799 \\
\hline 3.16 & -6.9 & -2.0 & 5868 & -4.9 & 5805 \\
\hline 5.17 & -1.5 & 0.8 & 5877 & 1.0 & 5811 \\
\hline 5.18 & -0.4 & 3.4 & 5882 & 1.2 & 5818 \\
\hline 5.19 & -0.4 & 2.1 & 5870 & 0.0 & 5816 \\
\hline 3.20 & -0.1 & 0.3 & 5859 & -3.4 & 5806 \\
\hline 3.21 & -3.3 & -1.2 & 5891 & -4.0 & 5832 \\
\hline 3.22 & 0.0 & 1.9 & 5880 & -0.6 & 5824 \\
\hline 5.23 & 0.9 & 4.8 & 5865 & 3.3 & 5813 \\
\hline 5.24 & 3.8 & 6.8 & 5843 & 2.5 & 5793 \\
\hline 5.25 & 2.2 & 4.9 & 5842 & 23 & 5792 \\
\hline
\end{tabular}

接控制水汽中 $\delta^{18} \mathrm{O}$ 的多家.

在唐古拉定点不同时间采集的样品中, 25 日以前降雪中的 $\delta^{18} \mathrm{O}$ 和 25 日以后降雪中的 
$\delta^{18} \mathrm{O}$ 相差达 $14.63 \%$ (表 1). 如前所述, $\delta^{18} \mathrm{O}$ 值都已校正到 $0{ }^{\circ} \mathrm{C}$, 因此温度差异对 $\delta^{18} \mathrm{O}$ 的影响 这一因子可以忽略. 所以 $14.63 \%$ 这一差㨁主要是由降水汽团的类型不同而产生的. 显然, 产 生如此明显差异的两个汽团应是性质完全不同的汽团. 所以将着眼点放在大陆汽团和海洋汽 团这样两个性质完全不同的汽团的差异上去解释 ${ }^{18} \mathrm{O}$ 的差异, 应是关键所在. 一般来说, 青 藏高原北部 5 月下旬至 6 月初是海洋汽团降水开始之时, 也即海洋汽团开始人侵之时. 进人 藏北的海洋汽团因沿途多次降水过程的分馏, 水汽中的 $\delta^{18} \mathrm{O}$ 含量已很少. 所以海洋汽团在这 儿凝结降雪时, 雪中的 $\delta^{18} \mathrm{O}$ 必然也小. 而在海洋汽团降水来临前的一段时间, 降水汽团主要 为高原内部局部水汽蒸发所产生的. 高原内部湖泊、河流为水汽蒸发的主要来源, 而这些湖 泊、河流特别是湖泊正好是 $\delta^{13} \mathrm{O}$ 富集之处. 因此, 从这些水面蒸发所产生的水汽, 携带的 $\boldsymbol{\delta}^{18} \mathrm{O}$ 含要亦高. 依此推理, 我们认为, 青藏高原唐古拉山地区 1989 年 5 月 13 日至 5 月 25 日以前 '的降雪主要为高原内部水汽蒸发形成的汽团所产生,而 5 月 25 日以后的降雪则主要为入侵的 海洋汽团所产生. 5 月 25 日前后温度的巨大差异也说明, 25 日前后降雪汽团的性质十 分 悬 殊. 为了说明这一问题, 我们在表 2 中不但列出了唐古拉山观测点 5 月 13 日至 5 月 25 日的 温度变化, 也列出了沦沱河、五道梁的温度、气压变化. 从表 2 可以看出, 唐古拉观测点 5 月 13 日至 23 日的日平均温度或升或降, 都维持在负温或 $0^{\circ} \mathrm{C}$ 附近. 5 月 23 日开始升温. 5 月 24 日, 也即降雪中 $\delta^{18} \mathrm{O}$ 突然降低的前一天, 日平均温度急剧升高, 达 $3.8^{\circ} \mathrm{C}$. 这说明在海洋汽 团降水产生前, 海洋汽团带来的高温影响已波及到本区. 即使在降大雪的 5 月 25 日, 日平均 温度仍在 $2^{\circ} 2^{\circ}$. 在沦沱河、五道梁两气象站, 除了有从 5 月 23 日开始的明显升温外, 还有气 压的明显降低. 为了更直观地认识这个问题, 我们绘制了 5 月 24 日天气图(图 2). 从天气图 可以看出, 这次降水的汽团起源于印度洋, 并经孟加拉湾进人青藏高原. 